Review

\title{
Endometrial Glandular Dysplasia (EmGD): morphologically and biologically distinctive putative precursor lesions of Type II endometrial cancers
}

\author{
Oluwole Fadare*1,2 and Wenxin Zheng ${ }^{3,4}$
}

\begin{abstract}
Address: ${ }^{1}$ Department of Pathology, Wilford Hall Medical Center, Lackland Air Force Base, San Antonio, Texas, USA, ${ }^{2}$ Department of Pathology, University of Texas Health Science Center at San Antonio, San Antonio, Texas, USA, ${ }^{3}$ Department of Pathology, Department of Obstetrics and Gynecology, and the Arizona Cancer Center, University of Arizona College of Medicine, Tucson, Arizona, USA and ${ }^{4}$ Department of Pathology and Hospital of Obstetrics and Gynecology, Shanghai Medical College, Fudan University, Shanghai, China

Email: Oluwole Fadare* - oluwolefadare@yahoo.com; Wenxin Zheng - zhengw@email.arizona.edu

* Corresponding author
\end{abstract}

Published: 8 February 2008

Diagnostic Pathology 2008, 3:6 doi:10.1 186/1746-1596-3-6

This article is available from: http://www.diagnosticpathology.org/content/3/l/6

(c) 2008 Fadare and Zheng; licensee BioMed Central Ltd.

This is an Open Access article distributed under the terms of the Creative Commons Attribution License (http://creativecommons.org/licenses/by/2.0), which permits unrestricted use, distribution, and reproduction in any medium, provided the original work is properly cited.
Received: 23 January 2008

Accepted: 8 February 2008

\begin{abstract}
In this article, the authors briefly review the historical evolution of the various putative precursor lesions for Type II endometrial cancers, with an emphasis on the newly defined "Endometrial Glandular Dysplasia (EmGD)". The evidentiary basis for delineating serous EmGD as the most probable precursor lesions to endometrial serous carcinoma is reviewed in detail. An argument is advanced for the discontinuation of the term serous "endometrial intraepithelial carcinoma (EIC)" as a descriptor for a supposedly intraepithelial, precancerous lesion. Preliminary evidence is also presented that suggests that there is a morphologically recognizable "clear cell EmGD" that probably represents a precancerous lesion to endometrial clear cell carcinomas.
\end{abstract}

\section{Background}

Endometrial cancers are the most frequently diagnosed malignancies of the female genital tract in the United States, with 39,080 new cases projected for 2007 [1]. Since 1983, two broad clinicopathologic subtypes of endometrial carcinomas have been recognized [2]. This conceptual classification has largely been supported by subsequent molecular-cytogenetic data, which has facilitated the acceptance of the so-called dualistic model of endometrial carcinogenesis [3-8]. Type I cancers, the prototype of which is the endometrioid histotype, occur in comparatively younger age group [3-8], appear to be related to unopposed estrogen stimulation [9-14], frequently express the estrogen and progesterone receptors $[7,13,14]$, arise in a background of glandular hyperplasia $[5,7,13,14]$, and has a relatively favorable prognostic pro- file [15]. Genetic alterations in Type 1 cancers include PTEN inactivation [16-19], beta-catenin (CTNNB1) mutations [17], and less frequently, microsatellite instability (related to inactivation of the MLH1 gene) [20,21], and activational mutations of the K-ras gene [22]. Type II cancers, the prototype of which is the endometrial serous carcinoma (ESC), and which was previously termed uterine papillary serous carcinoma (UPSC), typically occur in an older age group [3-8], frequently arise in a background of inactive or resting endometrium [3-8], and display a low frequency of expression of hormonal receptors $[13,14,23,24]$. Type II cancers also display frequent mutation and overexpression of the p53 [24-26] and HER2/ neu $[27,28]$ genes and proteins respectively, and have a comparatively poor prognosis independent of other factors [29-32]. This model has provided a valuable frame- 
work for the study of various aspects of endometrial carcinogenesis and for the potential development of therapeutic modalities that are pathway specific. Nonetheless, approximately 7400 deaths attributable to uterine corpus malignancies are projected for 2007 [1]. This relatively high mortality rate suggests that prevention and/or early detection remain highly essential approaches to the prevention of endometrial cancer-related mortality. One aspect of cancer prevention is the recognition of morphologically distinctive precursor lesions or "precancers" [33], so that a therapeutic intervention can be administered prior to the development of the well-developed malignancy. For more than 100 years, scientists have noted a spectrum of epithelial changes that have tentatively been considered to be precancerous in nature based on one or more of the following factors: a) the frequent coexistence of the putative precursor lesions with the well-developed malignancy as well as occasional morphologic transitions between them b) Shared epidemiologic, patient demographical, immunophenotypic and/or molecular genetic properties between the putative precursor lesions and their associated well-developed malignancies, and c) Longitudinal follow-up data that suggests that the putative precursor lesions confer an increased risk for the development of invasive malignancies [24,26,32,34-88]. These factors notwithstanding, the definition, full morphologic spectrum (including upper and lower limits) and clinical significance of the various putative endometrial precancers remain controversial. One factor contributing to this state of affairs is the ever-evolving nomenclature of endometrial precancers, a significant impediment to comparing data between studies. The purpose of this commentary is to summarize the current published data that forms the basis for the recent delineation of Endometrial Glandular Dysplasia (EmGD) as the most probable precancerous lesions for serous and probably clear cell carcinomas of the endometrium.

\section{Serous endometrial glandular dysplasia}

Reports describing variably papillary endometrial cancers with psammoma bodies have appeared in the literature since at least 1963 [89-93]. However, it was in the 1980 text by Hendrickson and Kempson that the concept of "serous" differentiation and aggressive behavior in these cancers was first emphasized [56]. Endometrial serous carcinomas (ESC) are now well recognized as uncommon endometrial cancers with distinctive morphologic features and a significantly worse overall survival as compared their endometrioid counterparts [29-32,94]. In 1992, Sherman et al [32] described 32 uterine carcinomas with a serous component, including 13 pure cases and 19 cases admixed with other histotypes. The authors noted the existence of "cytologically malignant cells closely resembling the invasive serous carcinoma in the surface endometrium adjacent to the tumor" [32]. This lesion was present in $89 \%$ of their 32 cases and was designated "intraepithelial carcinoma" by the authors [32]. Two reports published in 1995 appeared to be describing essentially the same "intraepithelial" lesion $[66,67]$. Spiegel et al [67] reviewed 518 hysterectomy specimens with endometrial cancers and found 89 cases "in which there were microscopic foci of malignant epithelium that failed to alter the architecture of an otherwise thin atrophic or weakly proliferative endometrium or endometrial polyp [67]." Sixty-six percent of the cancers associated with these foci had a serous component, and the author applied the designation "endometrial carcinoma in situ" [67]. In a study published later that year, Ambros et al [66] introduced the term "endometrial intraepithelial carcinoma" (EIC), and showed that this lesion was frequently and specifically associated with endometrial carcinomas with a serous component. In 1998, Zheng et al [70] used the designation "uterine surface carcinoma" to describe this lesion, noting that it is "often multicentric and behaves in a more aggressive fashion than regular in situ carcinomas" which rendered the previous designations inappropriate. In 2000, Wheeler et al [72] noted the difficulties and questionable validity of distinguishing EIC from stromal invasive but non-myoinvasive (superficial) ESC. The authors proposed the concept of "minimal uterine serous carcinoma", a term that would combine EIC, as previously defined [66], with small superficial ESC $(<1 \mathrm{~cm})$. "Serous EIC" is the recommended designation in the most recent WHO classification [88].

Pure serous EIC (serous EIC unassociated with a full blown and/or myoinvasive serous carcinomas) may potentially show extrauterine disease and/or peritoneal carcinomatosis [73]. Shared patterns of p53 mutations between the endometrial and extrauterine lesions argue in support of true origination of the latter from the former [74]. However, since pure serous EIC is so infrequently identified in isolation, there are no systematically collected data on precisely what percentage of them will show extrauterine disease. Non-myoinvasive (stage 1A) ESCs are known to show extrauterine disease in $17-67 \%$ of cases $[68,76,95,96]$.

In our opinion, the serous EIC designation, as used in this context to describe a supposedly intraepithelial, precancerous lesion, should be discarded. The notion that a "precancerous" lesion may display clinical malignancy (as evidenced by extrauterine extension) is indicative to us of a fundamental fallacy in the definition of the putative precursor lesion and is an obvious contradiction in terms. The distinction between serous EIC (as presently defined) and small "stromal-invasive" (stage 1A) ESC is a rather artificial one that is largely devoid of clinical significance and whose validity is questionable. Both are lined by identical, cytologically malignant cells $[32,66,67,70]$, 
both may show extrauterine disease $[68,76,95,96]$, and both require comprehensive surgical staging $[68,76,81,95,96]$. Rather, serous EIC is best conceptualized, and should be clinically managed as, small or early ESC [76]. Clement and Young [97] have outlined a similar approach, writing that they consider EIC "a tiny focus of serous carcinoma and do not qualify it further other than to note its size and location". Although tumor size is a well-established prognostic factor in malignancies of many organ systems, it is unclear if a comparable significance is operational in this particular malignancy, since diffuse extrauterine dissemination has been associated with microscopic endometrial lesions. However, one would intuitively expect the large "malignancy burden" of multifocal or extensive endometrial disease to increase the probability of extrauterine extension. Until the significance of lesion size is clarified, prudence should dictate that lesion size and disease extent be noted in the pathologic report but only after properly classifying the lesion as an ESC (rather than a serous EIC).

Given the aforementioned problems with serous EIC as a biologically valid precancer, Zheng et al [79] hypothesized that a morphologically identifiable lesion existed that bridged the gap between resting endometrium, in which ESC most frequently arises, and these so-called serous EIC lesions. The authors examined 108 hysterectomies ( 32 cases of classic ESC, 16 serous EIC, 60 endometrioid cancers). In $53 \%$ of the 32 cases of ESC and $1.7 \%$ of the 60 endometrioid cancers $(p<0.0001)$ one or more microscopic, morphologically atypical lesions that did not qualify for a serous EIC designation were identified [79]. These lesions were most commonly single glands or small glandular groups within the superficial endometrium or a flat layer of epithelium on the endometrial surface. These foci did not qualify for a serous EIC designation because their level of atypia was consistently not at the level seen in the adjacent well-developed serous cancers, which is a definitional requirement for serous EIC. These glands were designated "Endometrial Glandular Dysplasia" (EmGD) [79]. The typical EmGD focus showed epithelium lined by cells with nucleomegaly (24 times resting endometrium, as compared with 4-5 times in serous EIC), variably conspicuous nucleoli, variable hyperchromasia and loss of nuclear polarity [79] (Figure 1). Notably, the MIB-1 proliferative and p53 staining indices of the EmGD lesions were at least intermediate between the resting endometrium and the serous EIC. Based on their frequent and apparently specific association with ESCs, as well as their "intermediate" morphologic and immunophenotypic features (between benign and malignant epithelium), the authors speculated that EmGD represents the true precursor lesion of ESC [79], on the presumption that endometrial serous carcinogenesis is also a morphologically identifiable "stepwise process", rather than the spontaneous or "de novo" arising of ESC from benign endometrium. In a subsequent molecular study, Liang et al [77] provided preliminary evidence that suggested that although EmGD are not lined by comparably cytologically malignant cells, they are closer to EIC/ ESC than to resting endometrium. The patterns of loss of heterozygosity at 7 microsatellite polymorphic DNA markers were investigated in laser microdissected areas of EmGD and serous EIC/ESC. For 4 of the 7 markers, the frequency of LOH was higher in EmGD lesions as compared with resting endometrium, reaching statistical significance in 2 (TP53 and D1S162) and approaching such significance in the other 2 (D1S211 and D2S123). By contrast, when EmGD was compared to serous EIC/ESC, in only 1 locus -TP53 - was the frequency of LOH significantly different $(31.3 \%$ in EmGD versus $60 \%$ in serous EIC/ESC). Furthermore, in paired EmGD and serous EIC/ ESC samples (from the same patient), there was a high degree of concordance in the frequency of LOH [77]. The frequent mutation of the p53 gene in EmGD was confirmed in a subsequent study [98]. p53 mutations were identified in $0 \%, 43 \%, 72 \%$, and $96 \%$ of resting endometrium, EmGD, serous EIC and ESC, respectively. Furthermore, in excess of $50 \%$ of the uteri with the aforementioned neoplastic lesions showed at least one identical p53 gene mutation among lesions of EmGD, serous EIC and/or ESC $[98,99]$. These findings provide a molecular link between EmGD and ESC, one of the basic tenets of a putative precancer [33].

Recently, we investigated the endometrial biopsies that preceded hysterectomies in which ESC were diagnosed in an effort to determine whether EmGD lesions could be identified and if so, to estimate the duration between the diagnoses of the dysplastic and malignant lesions [82]. In 250 hysterectomies with ESC, preceding endometrial biopsies were available for evaluation in 27 cases. Of these 27 cases, EmGD lesions were identified in 9 cases $(33.3 \%)$. The average duration between the biopsies in which the EmGD lesions were identified and the hysterectomies in which the ESCs were diagnosed was 33 months (range 16-98 months). In the control group of 258 hysterectomies with benign diagnoses, only 1 EmGD was identified out of 29 preceding endometrial biopsies that were available for evaluation [82]. This provides preliminary evidence that EmGD may be associated with an increased risk of ESC, another tenet of a precancer [33]. At the protein level, the novel cytoplasmic marker IMP3 [Insulin-like growth factor II (IGF-II) mRNA binding Protein] provides further supportive evidence that links EmGD and ESC. Among endometrial cancers, IMP3 predominantly marks ESC. Zheng et al [100] demonstrated IMP3 expression is present in $14 \%$ of EmGD, $89 \%$ of serous EIC and 94\% of ESC. IMP3 expression was significantly less frequent in the other lesions studied: $0(0 \%)$ of 

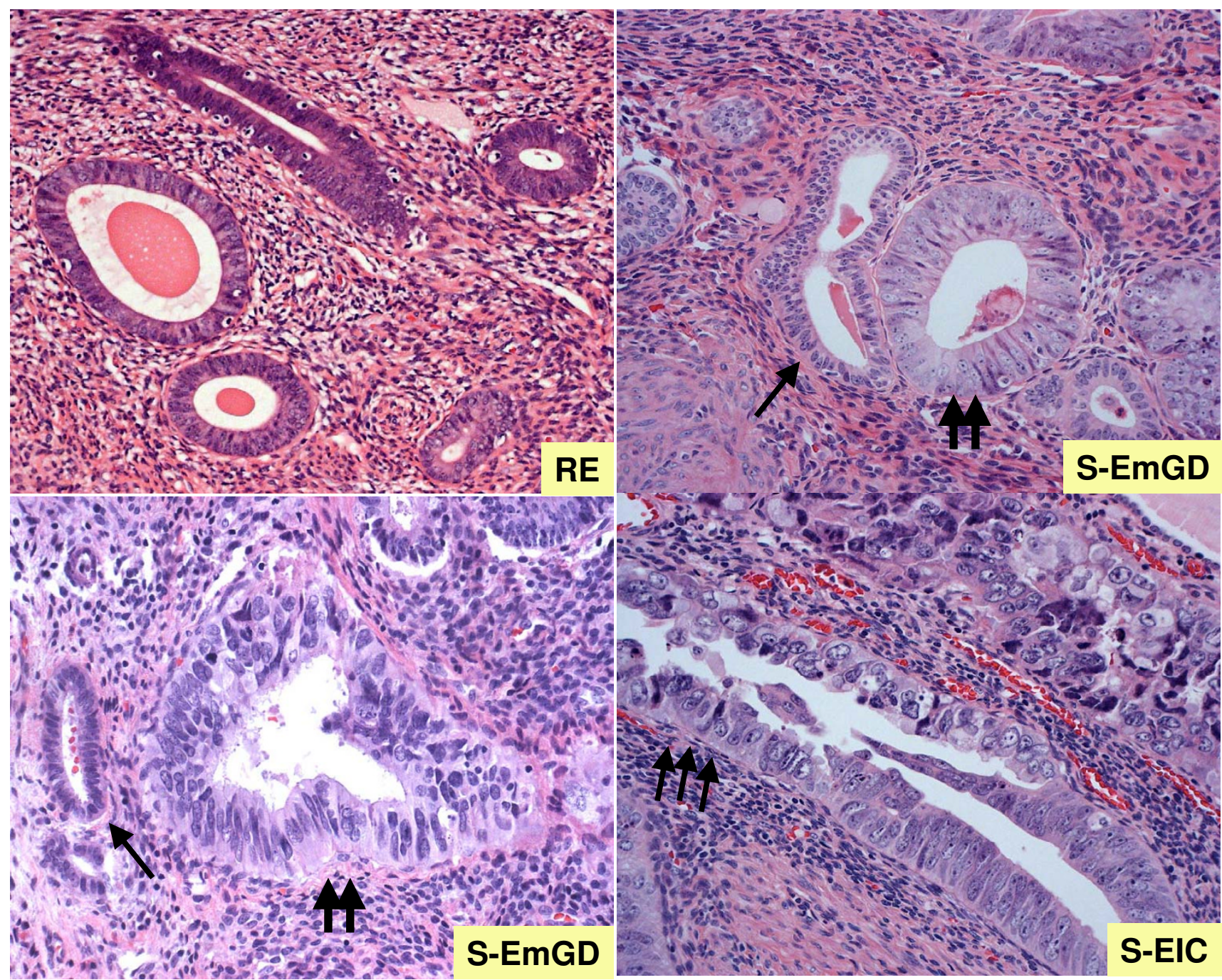

Figure I

Cytologic features of serous endometrial glandular dysplasia (S-EmGD, 2 arrows), as compared with resting endometrium (RE, $\mathrm{I}$ arrow) and the so-called serous endometrial intraepithelial carcinoma (S-EIC, 3 arrows).

$35,5(7 \%)$ of $70,0(0 \%)$ of $8,3(25 \%)$ of 12 , and $5(33 \%)$ of 15 cases of atypical hyperplasia, endometrioid, mucinous, clear cell carcinomas, and other malignancies, respectively.

To summarize the data from our group 1) EmGD is a morphologically identifiable, typically focal lesion that shows an association with endometrial cancers displaying serous differentiation [79]. 2) This association is common (53\% of hysterectomies with ESC) and apparently specific, at least relative to endometrioid adenocarcinomas [EmGD was seen in only $1.7 \%$ of hysterectomies with endometrioid cancers] [79] 3) EmGD are distinct from ESC/serous EIC as they are lined by cells whose degree of atypia falls short of the frankly malignant cells required of the latter; there are typically no direct morphologic transitions between EmGD and well-developed ESC [76,79]. 4) EmGD lesions display a proliferative and p53 staining index that is at least intermediate between resting endometrium and small ESC/serous EIC, which argues strongly against their being reactive in nature 5) Differential patterns of LOH for selected DNA markers in EmGD, ESC/serous EIC and resting endometrium indicates significant differences between EmGD and the resting endometrium in which they were identified and a kinship with ESC/serous EIC [77]. 6) EmGD was identified in $33 \%$ of the endometrial biopsies that preceded hysterectomies with ESC at an average duration of 33 months, but was present in only $3.4 \%$ of endometrial biopsies that preceded uteri with benign diagnoses [82]. Combined, these 
data provide evidence that EmGD is the most likely precursor lesion for ESC. EmGD fulfils most of the National Cancer Institute (NCI)'s criteria for a precancerous lesion [33]: (1) there is preliminary evidence that EmGD is associated with an increased risk of ESC; (2) partial molecular concordance in p53 mutations between EmGD and ESC provides one line of evidence that suggests that the latter arises from the former; (3) EmGD differs from the normal tissue from which it arises, and is morphologically recognizable as such; (4) EmGD is morphologically distinct from ESC, being characterized by cells that although more atypical than the background endometrial cells, cannot be characterized as cytologically malignant. (5) It is diagnosable by morphologic evaluation, with judicious use of immunohistochemical adjuncts such as p53, Ki67 and IMP3 in equivocal cases.

Nevertheless, it is unclear if EmGD represents an obligate precursor, or whether it is reversible. At the present time, however, we strongly advocate the discontinuation of the routine usage of the diagnostic terms "EIC" or "serous EIC". Small localized glandular or surface endometrial foci that are lined by malignant cells of the "serous-type" should simply be referred to as ESC, along with the size and if possible location of the lesion, as others have previously suggested [97].

\section{Clear cell endometrial glandular dysplasia}

Endometrial clear cell carcinoma (ECCC), a Type II cancer under the dualistic model, represents $1-5.5 \%$ of endometrial cancers [97,101-107]. Given the significant overlap that exists between ECCC and ESC in their morphologic [24,32], clinical [108] and global gene expression [109] attributes, it can be anticipated that an in situ lesion probably exists for ECCC. However, in contrast to the cervix, where sporadic examples of clear cell in situ lesions have long been reported [110-112], very little had been published on putative precursor lesions for ECCC until recently [86,87]. In 2004, Moid and Berezowski [86] described a distinctive lesion in the hysterectomy specimen of a 70-year-old woman which they designated "EIC, clear cell type". The lesion was comprised of surface epithelium and some glands that were lined by cells with "clear cytoplasm, marked nuclear pleomorphism, coarse chromatin, irregular nuclear membranes, and prominent eosinophilic nucleoli" and which occasionally had a hobnail appearance. The lesions showed "focal" staining for p53, a "moderate to high proliferative index", and no evidence of extrauterine extension [86]. Recently, our group attempted to more systematically characterize the clinicopathologic features of these putative precursor lesions. We evaluated the adjacent benign endometria in 14 cases of pure ECCC and 16 endometrial carcinomas with a greater than $10 \%$ ECCC component, in search of lesions that notably stood out from the background benign endometrium [87]. The lesions that we identified were single glands, small glandular clusters or segments of surface endometrium lined by cells that typically displayed cytoplasmic clarity and/or eosinophilia and a continuous gradient of nuclear atypicality. Based on the severity of the nuclear changes, we graded the lesions on a 3-tiered scale, with the grade 3 lesions essentially being lined by frankly malignant cells comparable to those of the adjacent malignancies. Morphologically, grade 3 lesions were essentially identical to clear cell EIC, while grade 1 and 2 lesions were designated clear cell EmGD (Figure 2). We

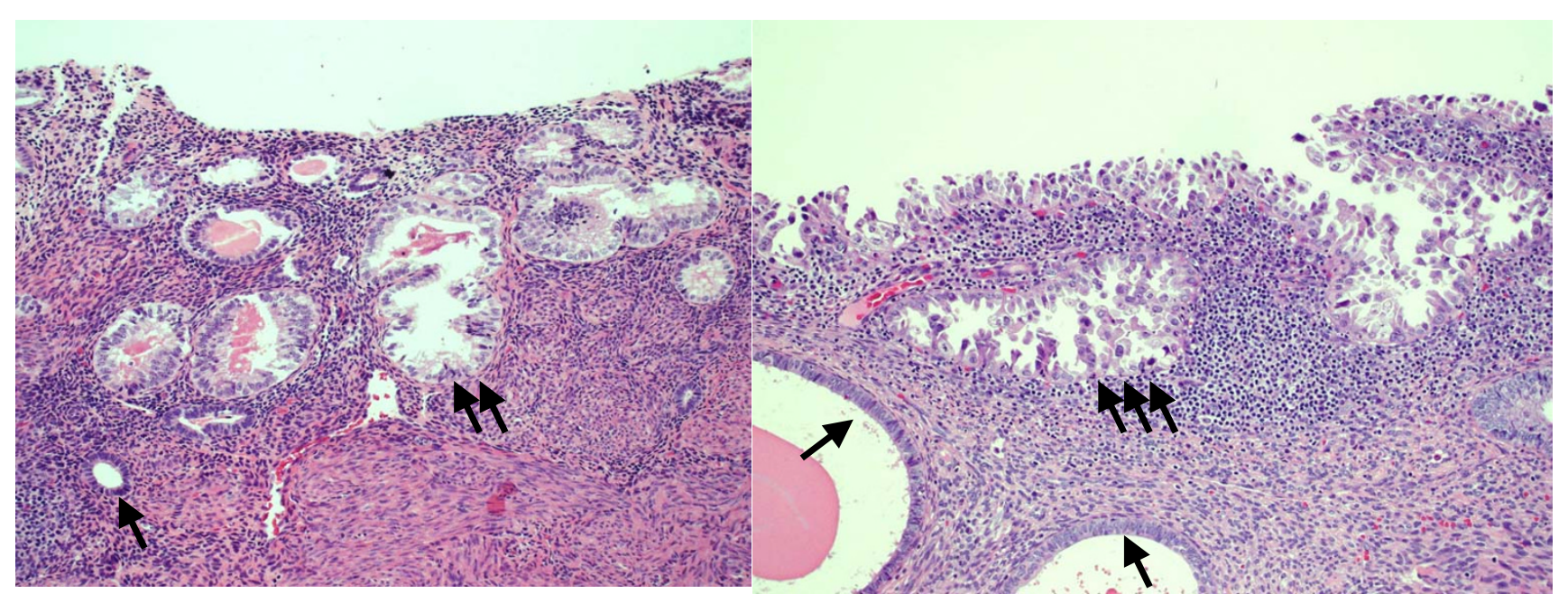

\section{Figure 2}

Resting endometrium (I arrow); clear cell endometrial glandular dysplasia (clear cell-EmGD, 2 arrows); clear cell endometrial intraepithelial carcinoma (clear cell-EIC, 3 arrows). 
tentatively considered these lesions the putative precancerous lesions for ECCC and proceeded to characterize their phenotype. At least one such putative precancer could be identified in 27 of the 30 cases evaluated, with an average of 2.5 foci per case [87]. Immunohistochemical p53 scores (0-9 scale) for these precancers were on average (4.5) lesser than the adjacent carcinomas (6.2) but significantly greater than the benign endometria (0). Similarly, the average proliferative index for the clear cell precancers $(45 \%)$ was intermediate between the carcinomas $(63 \%)$ and benign endometria (15\%). The lesions also showed notably reduced expression of ER and PR as compared with the adjacent benign endometria [87]. This composite of morphologic and immunophenotypic features resulted in lesions that were notably distinct from the background benign endometrium. In the control group of 38 benign uteri and 30 uteri with endometrioid cancers, no single immunohistochemically-confirmed clear cell precancer was identified [87]. Given their high rate of association with carcinomas having a clear cell component, their lack thereof in the control group of endometrioid cancers, their frequent occurrence in otherwise benign endometria and their aforementioned phenotype, we hypothesized that these lesions represent the precursor lesions of ECCC [87]. It is acknowledged, however, that significantly more research is required to define the full clinicopathologic spectrum of these distinctive lesions and to establish their precancerous nature according to NCI criteria [33].

\section{Summary}

Endometrial carcinomas are remarkably diverse in their biologic behavior. Perhaps more so than other organ systems, the histotype designation alone (endometrioid, serous, clear cell etc) provides a substantial amount of prognostic information. The present nomenclature for putative precursor lesions of endometrial cancers describes an incoherent amalgam that encompasses a lesion with very little malignancy risk (simple hyperplasia without atypia), and on the other end of the "spectrum", serous EIC, a lesion with inherent potential malignancy. Upon superficial inspection, this seems to rightfully mirror the biologic diversity of the invasive cancers for which they probably represent progenitors. However, a critical appraisal quickly reveals that at least a subset of the variability in the malignant potential of these precursors is attributable to definitional problems. Most importantly, as we have previously noted, we believe that the terms "EIC" or "Serous EIC" should be discarded as a means to describe an intraepithelial precancer. These lesions can show extrauterine spread and should thus be considered small uterine serous cancers. None of the other putative endometrial precancers have been reported to show extrauterine spread when present in isolation. For ESCs, we have presented morphologic, immunophenotypic, molecular and follow-up data that strongly suggests that EmGD represents their most probable precancerous lesion. EmGD fulfils most of the NCI requirements for a precancerous lesion [33]. For endometrial clear cell carcinomas, we similarly presented morphologic and immunophenotypic data that suggests that EmGD of the clear cell type represents their precancerous lesion, although there is insufficient data at present time to conclusively establish their precancerous nature by NCI standards.

Much is unknown about the nature, morphologic spectrum and clinical significance of endometrial precancers. However, their eventual characterization will likely start from their morphologic recognition. As such, the lesions described herein are worthy of segregation by pathologists and further study.

\section{Competing interests}

The author(s) declare that they have no competing interests.

\section{Authors' contributions}

OF and WZ co-wrote the manuscript

\section{Acknowledgements}

The views expressed in this article are those of the authors and do not reflect the official policy of the Department of Defense or other Departments of the United States Government. This work is supported in part by P30 CA23074 and the University of Arizona Department of Pathology start-up fund to WZ.

\section{References}

I. Jemal A, Siegel R, Ward E, Murray T, Xu J, Thun MJ: Cancer statistics, 2007. CA Cancer J Clin 2007, 57:43-66.

2. Bokhman JV: Two pathogenetic types of endometrial carcinoma. Gynecol Oncol 1983, I 5:10-7.

3. Sherman ME: Theories of endometrial carcinogenesis: a multidisciplinary approach. Mod Pathol 2000, I 3:295-308.

4. Lax SF, Kurman RJ: A dualistic model for endometrial carcinogenesis based on immunohistochemical and molecular genetic analyses. Verh Dtsch Ges Pathol 1997, 81:228-32.

5. Liu FS: Molecular carcinogenesis of endometrial cancer. Taiwan J Obstet Gynecol 2007, 46:26-32.

6. Matias-Guiu X, Catasus L, Bussaglia E, Lagarda H, Garcia A, Pons C, Munoz J, Arguelles R, Machin P, Prat J: Molecular pathology of endometrial hyperplasia and carcinoma. Hum Pathol 200I, 32:569-77.

7. Lax SF: Molecular genetic pathways in various types of endometrial carcinoma: from a phenotypical to a molecularbased classification. Virchows Arch 2004, 444:2 I3-23.

8. Deligdisch L, Holinka CF: Endometrial carcinoma: two diseases? Cancer Detect Prev 1987, 10:237-46.

9. Potischman N, Hoover RN, Brinton LA, Siiteri P, Dorgan JF, Swanson CA, Berman ML, Mortel R, Twiggs LB, Barrett RJ, Wilbanks GD, Persky V, Lurain JR: Case-control study of endogenous steroid hormones and endometrial cancer. J Natl Cancer Inst 1996, 88: II 27-35.

10. Shang Y: Molecular mechanisms of oestrogen and SERMs in endometrial carcinogenesis. Nat Rev Cancer 2006, 6:360-8.

II. Ettinger B, Golditch IM, Friedman G: Gynecologic consequences of long-term, unopposed estrogen replacement therapy. Maturitas 1988, 10:271-82

12. Gambrell RD Jr: Estrogens, progestogens and endometrial cancer. J Reprod Med 1977, I8:301-6. 
13. Demopoulos RI, Mesia AF, Mittal K, Vamvakas E: Immunohistochemical comparison of uterine papillary serous and papillary endometrioid carcinoma: clues to pathogenesis. Int J Gynecol Pathol 1999, 1 8:233-7.

14. Kounelis S, Kapranos N, Kouri E, Coppola D, Papadaki H, Jones MW: Immunohistochemical profile of endometrial adenocarcinoma: a study of $6 \mathrm{I}$ cases and review of the literature. Mod Pathol 2000, 13:379-88.

I5. Creasman WT, Odicino F, Maisonneuve P, Beller U, Benedet JL, Heintz AP, Ngan HY, Pecorelli S: Carcinoma of the corpus uteri. Int J Gynaecol Obstet 2003, 83(SuppI I):79-I I8.

16. Mutter GL: Pten, a protean tumor suppressor. Am J Pathol 200I, I 58: |895-1898.

17. Konopka B, Janiec-Jankowska A, Czapczak D, Paszko Z, Bidzinski M, Olszewski W, Goluda C: Molecular genetic defects in endometrial carcinomas: microsatellite instability, PTEN and betacatenin (CTNNBI) genes mutations. J Cancer Res Clin Oncol 2007, |33:36|-7|.

18. Risinger Jl, Hayes AK, Berchuck A, Barrett JC: PTEN/MMACI mutations in endometrial cancers. Cancer Res 1997, 57:4736-8.

19. Tashiro H, Blazes MS, Wu R, Cho KR, Bose S, Wang SI, Li J, Parsons $\mathrm{R}$, Ellenson LH: Mutations in PTEN are frequent in endometrial carcinoma but rare in other common gynecological malignancies. Cancer Res 1997, 57:3935-40.

20. Esteller M, Levine R, Baylin SB, Ellenson LH, Herman JG: MLHI promoter hypermethylation is associated with the microsatellite instability phenotype in sporadic endometrial carcinomas. Oncogene 1998, I7:24I3-24I7.

21. Faquin WC, Fitzgerald JT, Boynton KA, Mutter GL: Intratumora genetic heterogeneity and progression of endometrioid type endometrial adenocarcinomas. Gynecol Oncol 2000, 78: I 52 - I 57.

22. Velasco A, Bussaglia E, Pallares J, Dolcet X, Llobet D, Encinas M, Llecha N, Palacios J, Prat J, Matias-Guiu X: PIK3CA gene mutations in endometrial carcinoma: correlation with PTEN and K-RAS alterations. Hum Pathol 2006, 37:|465-72.

23. Sasano H, Comerford J, Wilkinson DS, Schwartz A, Garrett CT: Serous papillary adenocarcinoma of the endometrium. Analysis of proto-oncogene amplification, flow cytometry, estrogen and progesterone receptors, and immunohistochemistry. Cancer 1990, 65:|545-5।.

24. Lax SF, Pizer ES, Ronnett BM, Kurman RJ: Clear cell carcinoma of the endometrium is characterized by a distinctive profile of p53, Ki-67, estrogen, and progesterone receptor expression. Hum Pathol 1998, 29:55।-8.

25. Nordstrom B, Strang $P$, Lindgren A, Bergstrom R, Tribukait $B$ Endometrial carcinoma: the prognostic impact of papillary serous carcinoma (UPSC) in relation to nuclear grade, DNA ploidy and p53 expression. Anticancer Res 1996, 16:899-904.

26. Sherman ME, Bur ME, Kurman RJ: $\mathbf{p 5 3}$ in endometrial cancer and its putative precursors: Evidence for diverse pathways of tumorigenesis. Hum Pathol 1995, 26: I 268-I274.

27. Halperin R, Zehavi S, Habler L, Hadas E, Bukovsky I, Schneider D: Comparative immunohistochemical study of endometrioid and serous papillary carcinoma of endometrium. Eur J Gynaecol Oncol 2001, 22: 122-6.

28. Rolitsky CD, Theil KS, McGaughy VR, Copeland LJ, Niemann TH HER-2/neu amplification and overexpression in endometrial carcinoma. Int J Gynecol Pathol 1999, I 8: I 38-43

29. Lauchlan SC: Tubal (serous) carcinoma of the endometrium Arch Pathol Lab Med 1981, I 05:615-8.

30. Eifel PJ, Ross J, Hendrickson M, Cox RS, Kempson R, Martinez A Adenocarcinoma of the endometrium. Analysis of 256 cases with disease limited to the uterine corpus: treatment comparisons. Cancer 1983, 52:1026-31.

31. Lee KR, Belinson JL: Papillary serous adenocarcinoma of the endometrium: a clinicopathologic study of 19 cases. Gynecol Oncol 1992, 46:51-4.

32. Sherman ME, Bitterman P, Rosenshein NB, Delgado G, Kurman RJ: Uterine serous carcinoma. A morphologically diverse neoplasm with unifying clinicopathologic features. Am J Surg Pathol 1992, 16:600-10.

33. Berman JJ, Albores-Saavedra J, Bostwick D, Delellis R, Eble J, Hamilton SR, Hruban RH, Mutter GL, Page D, Rohan T, Travis W, Henson DE: Precancer: a conceptual working definition - results of a Consensus Conference. Cancer Detect Prev 2006, 30:387-94.
34. Cullen TS: Cancer of the Uterus: its pathology, symptomatology, diagnosis and treatment. New York: Appleton \& Co; 1900.

35. Kurman RJ, Kaminski PF, Norris HJ: The behavior of endometrial hyperplasia. A long-term study of "untreated" hyperplasia in I 70 patients. Cancer 1985, 56:403-12

36. Taylor HC Jr: Endometrial hyperplasia and carcinoma of the body of the uterus. Am J Obstet Gynecol 1932, 23:309-332.

37. Novak E, Yui E: Relation of endometrial hyperplasia to adenocarcinoma of the uterus. Am J Obstet Gynecol 1936, 32:674-698.

38. Beutler HK, Dockerty MB, Randall LM: Precancerous lesions of the endometrium. Am J Obstet Gynecol 1963, 86:433-443.

39. Steiner GJ, Kistner RW, Craig JM: Histological effects of progestins on hyperplasia and carcinoma in situ of the endometrium - further observations. Metabolism 1963, I 4:356-386.

40. Ruffolo EH, Cavanagh D, Marsden DE: Glandular intraepithelial neoplasia (GIN) - a unifying concept of the precursors of endometrial adenocarcinoma. Aust N Z J Obstet Gynaecol 1983. 23:220-5

41. Vellios F: Endometrial hyperplasias, precursors of endometrial carcinoma. Pathol Annu 1972, 7:201-229.

42. Speert $\mathrm{H}$ : The premalignant phase of endometrial carcinoma. Cancer 1952, 5:927-944.

43. Vellios F: Endometrial hyperplasia and carcinoma in situ. Gynecol Oncol 1974, 2:|52-161

44. Gusberg SB: Precursors of corpus carcinoma. Estrogens and adenomatous hyperplasia. Am J Obstet Gynecol 1947, 54:905-927.

45. Campbell PE, Barter RA: The significance of atypical endometrial hyperplasia. I Obstet and Gynaecol Br Commonw 196I, 68:668-672

46. Gusberg SB, Kaplan AL: Precursors of corpus cancer. IV. Adenomatous hyperplasia as stage 0 carcinoma of the endometrium. Am J Obstet Gynecol 1963, 87:662-678.

47. Hertig AT, Sommers SC: Genesis of endometrial carcinoma. I. Study of prior biopsies. Cancer 1949, 2:964-97I.

48. Gore H, Hertig AT: Carcinoma in situ of the endometrium. Am J Obstet Gynecol 1966, 94: I 34-I55.

49. Fox H: The endometrial hyperplasias. Obstet Gynecol Annu I984, 13:197-209.

50. Scully RE: Definition of precursors in gynecologic cancer. Cancer I98I, 48(2 Suppl):53I-7.

5I. Welch WR, Scully RE: Precancerous lesions of the endometrium. Hum Pathol 1977, 8:503-12.

52. Norris HJ, Tavassoli FA, Kurman RJ: Endometrial hyperplasia and carcinoma. Diagnostic considerations. Am J Surg Pathol 1983 , 7:839-47

53. Colgan TJ, Norris HJ, Foster W, Kurman RJ, Fox CH: Predicting the outcome of endometrial hyperplasia by quantitative analysis of nuclear features using a linear discriminant function. Int J Gynecol Pathol 1983, I:347-52.

54. Kurman RJ, Norris HJ: Evaluation of criteria for distinguishing atypical endometrial hyperplasia from well-differentiated carcinoma. Cancer 1982, 49:2547-59.

55. Tavassoli F, Kraus FT: Endometrial lesions in uteri resected for atypical endometrial hyperplasia. Am J Clin Pathol 1978, 70:770-9.

56. Hendrickson MR, Kempson RL: Surgical Pathology of the Uterine Corpus. Philadelphia: WB Saunders Co.; 1980.

57. Hunter JE, Tritz DE, Howell MG, DePriest PD, Gallion $\mathrm{HH}$, Andrews SJ, Buckley SB, Kryscio RJ, van Nagell JR Jr: The prognostic and therapeutic implications of cytologic atypia in patients with endometrial hyperplasia. Gynecol Oncol I 994, 55:66-7I.

58. Bergeron C, Nogales FF, Masseroli M, Abeler V, Duvillard P, MullerHolzner E, Pickartz H, Wells M: A multicentric European study testing the reproducibility of the WHO classification of endometrial hyperplasia with a proposal of a simplified working classification for biopsy and curettage specimens. Am J Surg Pathol 1999, 23: I 102-8.

59. Mutter GL, Baak JP, Crum CP, Richart RM, Ferenczy A, Faquin WC: Endometrial precancer diagnosis by histopathology, clonal analysis, and computerized morphometry. J Pathol 2000, 190:462-9.

60. Mutter GL: Endometrial intraepithelial neoplasia (EIN): will it bring order to chaos? The Endometrial Collaborative Group. Gynecol Oncol 2000, 76:287-90. 
61. Hecht JL, Mutter GL: Molecular and pathologic aspects of endometrial carcinogenesis. J Clin Oncol 2006, 24:4783-9I.

62. Mutter GL: Histopathology of genetically defined endometrial precancers. Int J Gynecol Pathol 2000, 19:30I-9.

63. Mutter GL: Diagnosis of premalignant endometrial disease. J Clin Pathol 2002, 55:326-3I.

64. Mutter GL, Zaino RJ, Baak JP, Bentley RC, Robboy SJ: Benign endometrial hyperplasia sequence and endometrial intraepithelial neoplasia. Int / Gynecol Pathol 2007, 26:103-14.

65. Baak JP, Mutter GL: EIN and WHO94. J Clin Pathol 2005, 58:I-6.

66. Ambros RA, Sherman ME, Zahn CM, Bitterman P, Kurman RJ: Endometrial intraepithelial carcinoma: a distinctive lesion specifically associated with tumors displaying serous differentiation. Hum Pathol 1995, 26:1260-7.

67. Spiegel GW: Endometrial carcinoma in situ in postmenopausal women. Am J Surg Pathol 1995, 19:417-32.

68. Carcangiu ML, Tan LK, Chambers JT: Stage IA uterine serous carcinoma: a study of I 3 cases. Am J Surg Pathol 1997, 2I: I 507-I 4.

69. Tashiro H, Isacson C, Levine R, Kurman RJ, Cho KR, Hedrick L: p53 gene mutations are common in uterine serous carcinoma and occur early in their pathogenesis. Am J Pathol 1997, 150: $177-85$

70. Zheng W, Khurana R, Farahmand S, Wang Y, Zhang ZF, Felix JC: p53 immunostaining as a significant adjunct diagnostic method for uterine surface carcinoma: precursor of uterine papillary serous carcinoma. Am / Surg Pathol 1998, 22:1463-73.

7I. Kovalev S, Marchenko ND, Gugliotta BG, Chalas E, Chumas J, Moll UM: Loss of p53 function in uterine papillary serous carcinoma. Hum Pathol 1998, 9:613-9.

72. Wheeler DT, Bell KA, Kurman RJ, Sherman ME: Minimal uterine serous carcinoma: diagnosis and clinicopathologic correlation. Am J Surg Pathol 2000, 24:A797-806.

73. Soslow RA, Pirog E, Isacson C: Endometrial intraepithelial carcinoma with associated peritoneal carcinomatosis. Am J Surg Pathol 2000, 24:726-32.

74. Baergen RN, Warren CD, Isacson C, Ellenson LH: Early uterine serous carcinoma: clonal origin of extrauterine disease. Int Gynecol Pathol 2001, 20:214-9.

75. McCluggage WG, Sumathi VP, McManus DT: Uterine serous carcinoma and endometrial intraepithelial carcinoma arising in endometrial polyps: report of 5 cases, including 2 associated with tamoxifen therapy. Hum Pathol 2003, 34:939-43.

76. Zheng W, Schwartz PE: Serous EIC as an early form of uterine papillary serous carcinoma: recent progress in understanding its pathogenesis and current opinions regarding pathologic and clinical management. Gynecol Oncol 2005, 96:579-82.

77. Liang SX, Chambers SK, Cheng L, Zhang S, Zhou Y, Zheng W: Endometrial glandular dysplasia: a putative precursor lesion of uterine papillary serous carcinoma. Part II: molecular features. Int J Surg Pathol 2004, I 2:3 I 9-3I.

78. Hui P, Kelly M, O'Malley DM, Tavassoli F, Schwartz PE: Minimal uterine serous carcinoma: a clinicopathological study of $\mathbf{4 0}$ cases. Mod Pathol 2005, 18:75-82.

79. Zheng W, Liang SX, Yu H, Rutherford T, Chambers SK, Schwartz PE: Endometrial glandular dysplasia: a newly defined precursor lesion of uterine papillary serous carcinoma. Part I: morphologic features. Int J Surg Pathol 2004, I 2:207-23.

80. Marchesoni D, Driul L, Mozzanega B, Nardelli GB, Parenti A: Intraepithelial G3 adenocarcinoma of the endometrium after tamoxifen treatment. Arch Gynecol Obstet 2005, 27 I:62-5.

81. Schwartz PE: The management of serous papillary uterine cancer. Curr Opin Oncol 2006, 18:494-9.

82. Zheng W, Liang SX, Yi X, Ulukus EC, Davis JR, Chambers SK: Occurrence of endometrial glandular dysplasia precedes uterine papillary serous carcinoma. Int J Gynecol Pathol 2007, 26:38-52.

83. Idrees MT, Schlosshauer P, Li G, Burstein DE: GLUTI and p63 expression in endometrial intraepithelial and uterine serous papillary carcinoma. Histopathology 2006, 49:75-8I.

84. Friedrich $M$, Villena-Heinsen $C$, Mink D, Bonkhoff $H$, Schmidt $W$ : Carcinosarcoma, endometrial intraepithelial carcinoma and endometriosis after tamoxifen therapy in breast cancer. Eur J Obstet Gynecol Reprod Biol 1999, 82:85-7.

85. Maksem JA, Lee SS: Endometrial intraepithelial carcinoma diagnosed by brush cytology and p53 immunostaining, and confirmed by hysterectomy. Diagn Cytopathol 1998, 19:284-7.
86. Moid F, Berezowski K: Pathologic quiz case: a 70-year-old woman with postmenopausal bleeding. Endometrial intraepithelial carcinoma, clear cell type. Arch Pathol Lab Med 2004, 128:el57-8.

87. Fadare O, Liang SX, Ulukus EC, Chambers SK, Zheng W: Precursors of endometrial clear cell carcinoma. Am J Surg Pathol 2006, 30:1519-30

88. Tavassoli FA, Devilee P, (Eds): World Health Organization Classification of Tumours. Pathology and Genetics of Tumours of the Breast and female genital Organs. IARC Press. Lyon; 2003.

89. Factor SM: Papillary adenocarcinoma of the endometrium with psammoma bodies. Arch Pathol 1974, 98:20I-5.

90. Hameed K, Morgan DA: Papillary adenocarcinoma of endometrium with psammoma bodies. Histology and fine structure. Cancer 1972, 29:1326-35.

91. Karpas CM, Bridge MF: Endometrial adenocarcinoma with psammomatous bodies. Am J Obstet Gynecol 1963, 87:935-4I.

92. LiVolsi VA: Adenocarcinoma of the endometrium with psammoma bodies. Obstet Gynecol 1977, 50:725-8.

93. Cefis F, Carinelli SG, Marzi MM, Senzani F: Endometrial adenocarcinoma with psammoma bodies. Tumori 1979, 65: 1979359-62.

94. Hendrickson M, Ross J, Eifel P, Martinez A, Kempson R: Uterine papillary serous carcinoma: a highly malignant form of endometrial adenocarcinoma. Am J Surg Pathol 1982, 6:93-108.

95. Chan JK, Loizzi V, Youssef M, Osann K, Rutgers J, Vasilev SA, Berman ML: Significance of comprehensive surgical staging in noninvasive papillary serous carcinoma of the endometrium. Gynecol Oncol 2003, 90: 181-5.

96. Gehrig PA, Groben PA, Fowler WC Jr, Walton LA, Van Le L: Noninvasive papillary serous carcinoma of the endometrium. Obstet Gynecol 200I, 97:153-7.

97. Clement PB, Young RH: Non-endometrioid carcinomas of the uterine corpus: a review of their pathology with emphasis on recent advances and problematic aspects. Adv Anat Pathol 2004, I I: I 17-42.

98. Jia L, Liu Y, Yi X, Miron A, Crum CP, Kong B, Zheng W: Endometrial Glandular Dysplasia with Frequent p53 Gene Mutation:A Genetic Evidence Supporting its Precancer Nature for Endometrial Serous Carcinoma. Clin Cancer Res in press.

99. Yi X, Zheng W: Endometrial glandular dysplasia and endometrial intraepithelial neoplasia. Curr Opin Obstet Gynecol 2008, 20:20-25

100. Zheng W, Yi X, Fadare O, Liang SX, Martel M, Schwartz PE, Dressler K, Jiang Z: The Oncofetal Protein IMP3: A Novel Biomarker for Endometrial Serous Carcinoma. Am J Surg Pathol 2008, 32:304-315.

10I. Giri PG, Schneider V, Belgrad R: Clear cell carcinoma of the endometrium: an uncommon entity with a favorable prognosis. Int J Radiat Oncol Biol Phys 198I, 7:1383-7.

102. Christopherson WM, Alberhasky RC, Connelly PJ: Carcinoma of the endometrium: I. A clinicopathologic study of clear-cell carcinoma and secretory carcinoma. Cancer 1982, 49:15II-23.

103. Abeler VM, Kjorstad KE: Clear cell carcinoma of the endometrium: a histopathological and clinical study of $\mathbf{9 7}$ cases. Gynecol Oncol 1991, 40:207-17.

104. Kurman RJ, Scully RE: Clear cell carcinoma of the endometrium: an analysis of 21 cases. Cancer 1976, 37:872-82.

105. Silverberg SG, De Giorgi LS: Clear cell carcinoma of the endometrium. Clinical, pathologic, and ultrastructural findings. Cancer 1973, 31: | |27-40.

106. Webb GA, Lagios MD: Clear cell carcinoma of the endometrium. Am J Obstet Gynecol 1987, 1 56: | 486-91.

107. Kanbour-Shakir A, Tobon H: Primary clear cell carcinoma of the endometrium: a clinicopathologic study of 20 cases. Int J Gynecol Pathol 1991, 10:67-78.

108. Carcangiu ML, Chambers JT: Early pathologic stage clear cell carcinoma and uterine papillary serous carcinoma of the endometrium: comparison of clinicopathologic features and survival. Int J Gynecol Pathol 1995, 14:30-8.

109. Risinger JI, Maxwell GL, Chandramouli GV, Jazaeri A, Aprelikova O, Patterson T, Berchuck A, Barrett IC: Microarray analysis reveals distinct gene expression profiles among different histologic types of endometrial cancer. Cancer Res 2003, 63:6- II.

110. Hasumi K, Ehrmann RL: Clear cell carcinoma of the uterine endocervix with an in situ component. Cancer 1978, 42:2435-8. 
III. Parker JC Jr, Van Nagell JR Jr, Harralson JD: The mesonephroid (hypernephroid) carcinomatous pattern - a rare variant of primary endocervical adenocarcinoma. Cancer 1973, 32:259-65.

112. Roth LM, Hornback NB: Clear-cell adenocarcinoma of the cervix in young women. Cancer 1974, 34:I76I-8.

Publish with Biomed Central and every scientist can read your work free of charge

"BioMed Central will be the most significant development for disseminating the results of biomedical research in our lifetime. " Sir Paul Nurse, Cancer Research UK

Your research papers will be:

- available free of charge to the entire biomedical community

- peer reviewed and published immediately upon acceptance

- cited in PubMed and archived on PubMed Central

- yours - you keep the copyright

Submit your manuscript here:

http://www.biomedcentral.com/info/publishing_adv.asp 